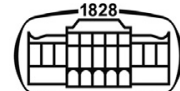

AKADÉMIAI KIADÓ

Acta Chromatographica

34 (2022) 1, 1-11

DOl:

$10.1556 / 1326.2021 .00885$

(c) 2021 The Author(s)

\section{ORIGINAL RESEARCH} PAPER

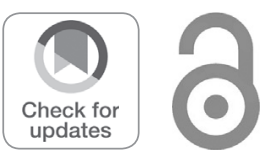

Corresponding author

Tel.: +381 113951334

fax: +381113972840 .

E-mail: anna@pharmacy.bg.ac.rs

\section{AKJournals}

\title{
Robust optimization of gradient RP HPLC method for simultaneous determination of ivabradine and its eleven related substances by AQbD approach
}

JOVANA TOMIĆ ${ }^{1}$, NEVENA DJAJIĆ ${ }^{2}$, DANICA AGBABA ${ }^{1}$, BILJANA OTAŠEVIĆ ${ }^{2}$, ANDJELIJA MALENOVIĆ ${ }^{2}$ and ANA PROTIĆ ${ }^{2 *}$

\author{
${ }^{1}$ Department of Pharmaceutical Chemistry, University of Belgrade, Faculty of Pharmacy, Vojvode \\ Stepe 450, 11 152, Belgrade, Serbia \\ ${ }^{2}$ Department of Drug Analysis, University of Belgrade, Faculty of Pharmacy, Vojvode Stepe 450, 11 \\ 221 Belgrade, Serbia
}

Received: December 22, 2020 • Accepted: January 23, 2021

Published online: February 23, 2021

\begin{abstract}
This paper is aimed at developing a gradient elution reversed-phase high-performance liquid chromatography (RP-HPLC) method for the separation of a complex mixture composed of ivabradine and its eleven impurities, in a reasonable timeframe. In order to obtain a robust and reliable HPLC method for separation of this mixture, Analytical Quality by Design (AQbD) was applied. This approach demonstrated to be useful in development of a long lasting life cycle methods. Four chromatographic variables were defined as key method parameters (KMPs) and optimized towards the analytical target profile (ATP). Designated KMPs were initial and final amount of acetonitrile in the mobile phase, $\mathrm{pH}$ value of the aqueous phase and gradient time, while resolutions of critical peak pairs were denoted as critical method attributes (CMAs). Relationships between KMPs and CMAs were obtained with the aid of Design of Experiments (DoEs) methodology among which Box-Behnken design (BBD) was employed to gain valid mathematical models. Obtained mathematical equations were used to construct the Design Space (DS) and select reliable optimal separation conditions. They included $11 \%(\mathrm{v} / \mathrm{v})$ and $34 \%(\mathrm{v} / \mathrm{v})$ of initial and final amount of acetonitrile, respectively, as well as $45 \mathrm{~min}$ of gradient elution time and $20 \mathrm{mM}$ ammonium acetate as aqueous mobile phase with $\mathrm{pH}$ set to 7.35 . The possibility to separate the diastereoisomers of impurity $\mathrm{X}$ was also evaluated. It was demonstrated that this separation could not be achieved in gradient elution mode within the defined variable domains and in a reasonable time span. The developed method was validated according to ICH Q2 (R1) guideline and met all the required criteria.
\end{abstract}

\section{KEYWORDS}

ivabradine, gradient elution RP-HPLC method, Box-Behnken design, Analytical Quality by Design

\section{INTRODUCTION}

Ivabradine acts as sinus node 'If currents' blocker, the 'pacemaker' that controls the heart's contractions thus regulating the heart rate. Blocking these currents causes lowering of the heart rate, therefore ivabradine is used in treatment of chronic stable angina pectoris and myocardial ischemia with an optimal tolerability profile $[1,2]$. Molecule has one asymmetric carbon atom of $(S)$ configuration with no bioconversion demonstrated in vivo. Being a relatively novel heart rate lowering agent, there are only a few High-Performance Liquid Chromatography (HPLC) and Ultra High-Performance Liquid Chromatography (UHPLC) methods employing both fluorescence detection and mass spectrometry (MS) for determination of ivabradine and its metabolites in biological matrices (urine and plasma) [3-7]. 


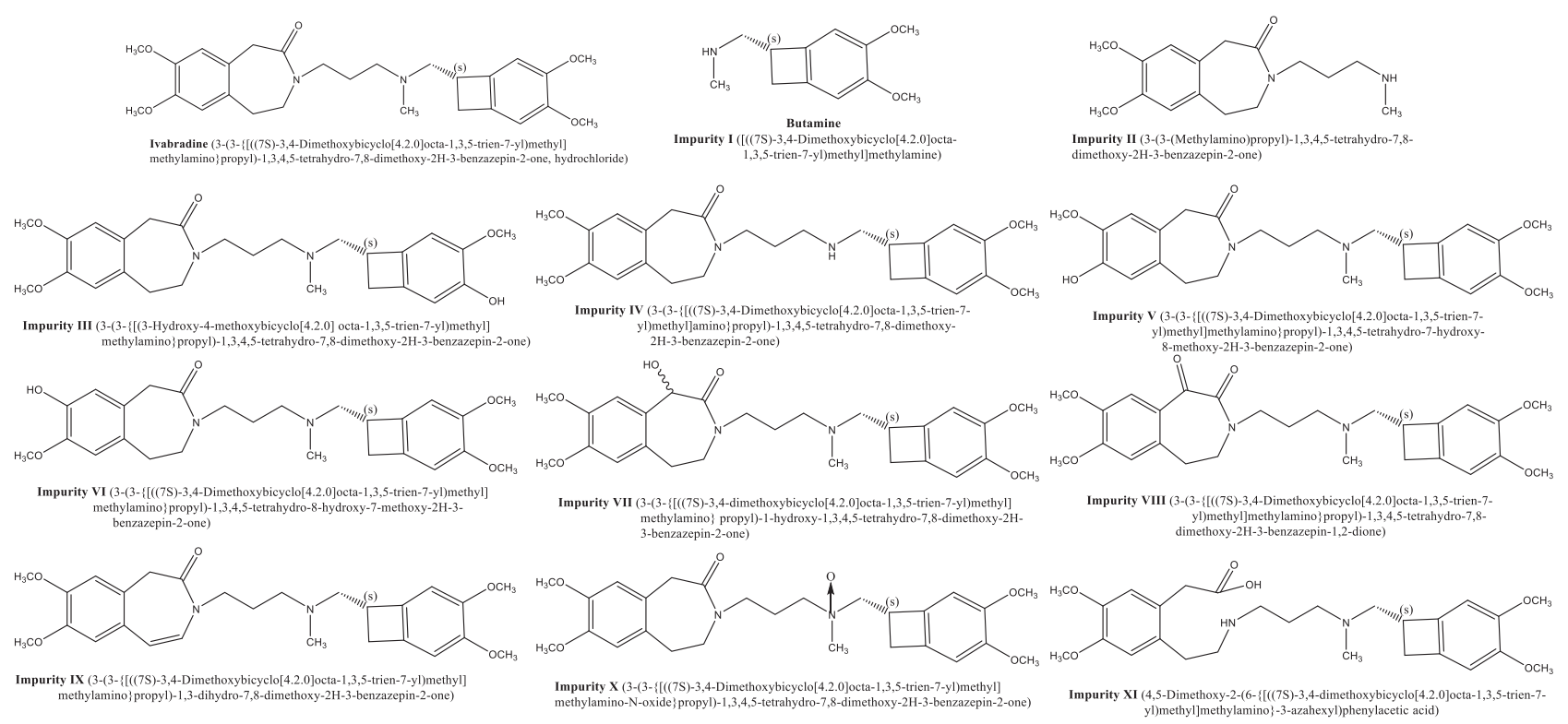

Fig. 1. Chemical structures of ivabradine and its eleven impurities

Literature survey revealed stability indicating methods for determination of ivabradine in tablets' formulation. These methods included HPLC with isocratic elution, HPTLC and spectrophotometric methods [8-10]. Hydrolytic degradation of ivabradine in $\mathrm{HCl}$ and $\mathrm{H}_{2} \mathrm{SO}_{4}$ with simultaneous determination of ivabradine and its five potential degradation products was investigated by gradient elution liquid chromatography coupled with high resolution MS (LC-HRMS/MS) [11]. In addition to characterization of the obtained degradation products under different stress conditions (acid and alkaline hydrolysis, oxidation, photolysis), there was a study addressing ivabradine in silico toxicology prediction [12]. One of the potential synthesis pathways of ivabradine involves utilization of ketone based solvents, which may be the source of methyl vinyl ketone, a potential genotoxic impurity. For that reason, reversed-phase highperformance liquid chromatography (RP-HPLC) has been developed for trace level quantification of methyl vinyl ketone [13]. However, according to the available literature, there are still no papers dealing with comprehensive purity assessment of ivabradine as active pharmaceutical ingredient (API), especially in solid dosage form. In our previous publication, RP-HPLC method with isocratic elution for efficient separation of ivabradine and its eleven impurities (Fig. 1) was presented for the first time [14]. Impurities I-IX originated from both synthesis pathway and degradation occurring in the dosage form. Conversly, impurities X and $\mathrm{XI}$ are only potential degradation products of ivabradine. Compound IV is both an impurity and metabolite with $40 \%$ activity of the parent drug, while V and VI are impurities and inactive metabolites. The proposed mixture shows high level of complexity since it contains compounds of similar polarity, three positional isomers (impurities III, V, and VI), keto-enol tautomers of impurity VII, denoted as VII_1 and VII_2, and diastereoisomers of impurity X, labeled as $\mathrm{X} \_1$ and $\mathrm{X} \_2$. In the previous paper, it was demonstrated that diastereoisomers could be separated with acetonitrile as organic modifier in the mobile phase, while the addition of methanol precluded the separation. Considering the presented findings together with long chromatographic run time as the main drawback of the previously developed method, two aims arouse. The first one was to develop a gradient elution chromatographic method for the simultaneous determination of ivabradine and its eleven impurities with improvement reflected in acceptable run time. Another aim was to investigate whether separation of diastereoisomers is possible in gradient elution mode when acetonitrile is used as organic modifier, knowing the different retention mechanisms in gradient elution compared to isocratic.

In order to fulfill the above mentioned goals, Analytical Quality by Design (AQbD) approach was applied, which enabled reliable and comprehensive conclusions regarding the given chromatographic system. AQbD is considered as systematic approach, taking advantage over design of experiments (DoEs) and statistical screening for method parameter operational space towards method robustness considerations. AQbD takes into consideration both scientific facts and quality control requirements, so its application to method development is also well received by pharmaceutical industry $[15,16]$.

Quality by Design (QbD) has been utilized for more than a decade and labeled as AQbD when applied in the area of analytical method development $[15,16]$. Analytical target profile (ATP) must be defined prior to the optimization process. ATP includes all goals that one method must fulfill and are usually associated with robustness, selectivity and validation criteria of the analytical method. All steps of the method (sample preparation, sample analysis, data analysis) that significantly influence the change of ATP are defined as critical method parameters (CMPs). Within each CMP, a set of method parameters that influence the ATP can be defined 
and they are designated as key method parameters (KMPs). In order to properly link the KMPs with ATP, critical method attributes (CMAs) must be selected. For investigation of the relationship between KMPs and CMAs, DoE methodology is generally used. DoE is useful in different stages of method development. Namely, in the screening phase DoE can reduce the number of KMPs while in the optimization phase it can help in defining valid mathematical models and uncertainties related to each key method parameter (KMP). Furthermore, DoE is crucial to adequately define KMP through the plan of experiments and iterative risk assessment. In this way, it enables profound understanding of each KMP's impact on the CMAs and consequently ATP itself [15-19]. When taking into account uncertainty of KMPs, Design Space (DS) can be easily constructed. The DS is defined as "the multidimensional combination and interaction of input variables (e.g., material attributes) and process parameters that have been demonstrated to provide assurance of quality" [19]. In other words, DS represents the domain of KMPs where CMAs meet predefined acceptable values. In this way, not only for one set of experimental conditions but the whole experimental region enables suitable chromatographic analysis. The chromatographic conditions in the middle of DS warrant the robust, non-prone to unexpected deviations and a long life cycle of the proposed analytical method. The life cycle of the method is very important regarding the fact that one should last from drug development phase to stability studies and long term stability studies phase [16, 17, 20-23].

\section{MATERIALS AND METHODS}

\section{Chemicals and reagents}

All reagents used in the experimental work were of analytical grade. HPLC grade acetonitrile was purchased from Merck (Darmstadt, Germany). Water of HPLC purity was obtained by filtering through Simplicity 185 system (Millipore, Billerica, MA, USA), ammonium acetate and ammonia solution $25 \%(\mathrm{v} / \mathrm{v})$ (Merck, Darmstadt, Germany) were used to prepare the aqueous part of the mobile phase. Reference standard substances of ivabradine hydrochloride and its eleven impurities were kindly donated by Les Laboratories Servier (Paris, France).

\section{Chromatographic conditions}

Dionex Ultimate 3000 (Thermo Fisher Scientific, USA) consisting of binary Ultimate 3000 HPG 3200 pump, Ultimate 3000 WPS autosampler, Ultimate 3000 TCC column thermostat, and Ultimate 3000 DAD (Chromeleon CDS, version 7.2, used for data collection and analysis) was utilized as the chromatographic system.

Separations were performed on Atlantis C18 column, 4.6 $\mathrm{mm} \times 150 \mathrm{~mm}, 3 \mu \mathrm{m}$ particle size (Waters, Milford, Massachusetts, USA) with temperature set to $25{ }^{\circ} \mathrm{C}$. The flow rate was $1 \mathrm{~mL} \mathrm{~min}^{-1}$, while $\mathrm{UV}$ detection was performed at $220 \mathrm{~nm}$. The samples' volumes injected into the HPLC system were $10 \mu \mathrm{L}$. The analysis was carried out in the gradient elution mode with mobile phase A, consisting of 20 $\mathrm{mM}$ ammonium acetate buffer, $\mathrm{pH} 7.35$ adjusted with the addition of ammonium hydroxide solution, and mobile phase $\mathrm{B}$, consisting of acetonitrile. During method optimization, the $\mathrm{pH}$ of the aqueous mobile phase was varied between 6.00 and 7.50 with an addition of a proper amount of $25 \%$ ammonium hydroxide solution. In order to ensure its stability, mobile phase was prepared in a quantity sufficient for daily use. The mobile phase was filtered through a nylon membrane filter with a $0.45 \mu \mathrm{m}$ pore size (Agilent Technologies, Santa Clara, USA) and degassed in an ultrasonic bath prior to use. Optimal chromatographic conditions included a linear gradient from 11 to $34 \%(\mathrm{v} / \mathrm{v})$ mobile phase $\mathrm{B}$, in $45 \mathrm{~min}$, followed by a re-equilibration time of 10 min.

\section{Preparation of solutions}

Standard solutions. Standard stock solutions were prepared by dissolving the respective amount of reference standard substances in acetonitrile:water mixture 50:50 (v/v) to obtain the following concentrations: $3.84 \mathrm{mg} \mathrm{mL}^{-1}$ for ivabradine hydrochloride, $52.00 \mu \mathrm{g} \mathrm{mL}^{-1}$ for impurity I, $37.00 \mu \mathrm{g} \mathrm{mL}^{-1}$ for impurity II, $56.00 \mu \mathrm{g} \mathrm{mL}{ }^{-1}$ for impurity III, $40.00 \mu \mathrm{g}$ $\mathrm{mL}^{-1}$ for impurity IV, $40.00 \mu \mathrm{g} \mathrm{mL}^{-1}$ for impurity $\mathrm{V}, 56.00$ $\mu \mathrm{g} \mathrm{mL}^{-1}$ for impurity VI, $40.00 \mu \mathrm{g} \mathrm{mL}^{-1}$ for impurity VII, $40.00 \mu \mathrm{g} \mathrm{mL}^{-1}$ for impurity VIII, $35.00 \mu \mathrm{g} \mathrm{mL}^{-1}$ for impurity IX, $36.00 \mu \mathrm{g} \mathrm{mL}^{-1}$ for impurity $\mathrm{X}, 48.00 \mu \mathrm{g} \mathrm{mL}^{-1}$ for impurity XI.

Solutions for calibration. To obtain the calibration curve, eight solutions of ivabradine hydrochloride and its related impurities were prepared in the concentration range from 1.20 to $3.60 \mathrm{mg} \mathrm{mL}^{-1}$ for ivabradine hydrochloride, $1.66-$ $6.00 \mu \mathrm{g} \mathrm{mL}^{-1}$ for impurity I, $1.55-3.73 \mu \mathrm{g} \mathrm{mL}^{-1}$ for impurity II, $0.95-2.28 \mu \mathrm{g} \mathrm{mL}^{-1}$ for impurity III, $0.80-1.92 \mu \mathrm{g}$ $\mathrm{mL}^{-1}$ for impurity IV, $0.68-1.63 \mu \mathrm{g} \mathrm{mL}^{-1}$ for impurity $\mathrm{V}$, $1.12-2.69 \mu \mathrm{g} \mathrm{mL}^{-1}$ for impurity VI, $2.40-17.28 \mu \mathrm{g} \mathrm{mL}^{-1}$ for impurity VII, $0.80-5.76 \mu \mathrm{g} \mathrm{mL}{ }^{-1}$ for impurity VIII, $0.38-$ $0.92 \mu \mathrm{g} \mathrm{mL}^{-1}$ for impurity IX, $1.08-2.59 \mu \mathrm{g} \mathrm{mL} \mathrm{m}^{-1}$ for impurity $\mathrm{X}$, and $2.02-4.84 \mu \mathrm{g} \mathrm{mL}^{-1}$ for impurity XI. These dilutions of standard stock solutions were prepared with the solvent consisting of acetonitrile and $20 \mathrm{mM}$ ammonium acetate buffer solution $\mathrm{pH} 7.33$ (15:75, v/v).

Solutions for estimating the method's accuracy. To determine the accuracy, a placebo mixture was spiked with known amount of reference standard substance of ivabradine hydrochloride and its eleven impurities. Reference standard of the active compound was added to obtain solutions corresponding to 80,100 , and $120 \%$ of the nominal concentration. Also, the placebo mixture is spiked with impurities' reference standards to obtain LOQ, 100 and $120 \%$ concentration levels. Each solution was analyzed in triplicate. Previously constructed calibration curves were used to calculate the recovery values of active pharmaceutical ingredient and impurities, as a measure of accuracy. 
Mixture 1 contained $1.92 \mathrm{mg} \mathrm{mL}^{-1}$ of ivabradine hydrochloride, $1.66 \mu \mathrm{g} \mathrm{mL}^{-1}$ of impurity I, $1.55 \mu \mathrm{g} \mathrm{mL}^{-1}$ of impurity II, $0.95 \mu \mathrm{g} \mathrm{mL}^{-1}$ of impurity III, $0.80 \mu \mathrm{g} \mathrm{mL}^{-1}$ of impurity IV, $0.68 \mu \mathrm{g} \mathrm{mL}^{-1}$ of impurity $\mathrm{V}, 1.12 \mu \mathrm{g} \mathrm{mL}^{-1}$ of impurity VI, $2.40 \mu \mathrm{g} \mathrm{mL}^{-1}$ of impurity VII, $0.80 \mu \mathrm{g} \mathrm{mL}^{-1}$ of impurity VIII, $0.38 \mu \mathrm{g} \mathrm{mL}^{-1}$ of impurity IX, $1.08 \mu \mathrm{g} \mathrm{mL}^{-1}$ of impurity $\mathrm{X}, 2.02 \mu \mathrm{g} \mathrm{mL}^{-1}$ of impurity XI.

Mixture 2 contained $2.40 \mathrm{mg} \mathrm{mL} \mathrm{m}^{-1}$ of ivabradine hydrochloride, $5.00 \mu \mathrm{g} \mathrm{mL}^{-1}$ of impurity I, $3.11 \mu \mathrm{g} \mathrm{mL}^{-1}$ of impurity II, $1.90 \mu \mathrm{g} \mathrm{mL}^{-1}$ of impurity III, $1.60 \mu \mathrm{g} \mathrm{mL}^{-1}$ of impurity IV, $1.36 \mu \mathrm{g} \mathrm{mL}^{-1}$ of impurity $\mathrm{V}, 2.24 \mu \mathrm{g} \mathrm{mL}^{-1}$ of impurity VI, $14.40 \mu \mathrm{g} \mathrm{mL}^{-1}$ of impurity VII, $4.80 \mu \mathrm{g} \mathrm{mL}^{-1}$ of impurity VIII, $0.77 \mu \mathrm{g} \mathrm{mL}^{-1}$ of impurity IX, $2.16 \mu \mathrm{g} \mathrm{mL}^{-1}$ of impurity X, $4.03 \mu \mathrm{g} \mathrm{mL} \mathrm{m}^{-1}$ of impurity XI.

Mixture 3 contained $2.88 \mathrm{mg} \mathrm{mL} \mathrm{m}^{-1}$ of ivabradine hydrochloride, $6.00 \mu \mathrm{g} \mathrm{mL}^{-1}$ of impurity I, $3.73 \mu \mathrm{g} \mathrm{mL}^{-1}$ of impurity II, $2.28 \mu \mathrm{g} \mathrm{mL}^{-1}$ of impurity III, $1.92 \mu \mathrm{g} \mathrm{mL}^{-1}$ of impurity IV, $1.63 \mu \mathrm{g} \mathrm{mL}^{-1}$ of impurity $\mathrm{V}, 2.69 \mu \mathrm{g} \mathrm{mL}^{-1}$ of impurity VI, $17.28 \mu \mathrm{g} \mathrm{mL}^{-1}$ of impurity VII, $5.76 \mu \mathrm{g} \mathrm{mL}^{-1}$ of impurity VIII, $0.92 \mu \mathrm{g} \mathrm{mL}^{-1}$ of impurity IX, $2.59 \mu \mathrm{g} \mathrm{mL}^{-1}$ of impurity X, $4.84 \mu \mathrm{g} \mathrm{mL} \mathrm{m}^{-1}$ of impurity XI.

Solutions for estimating the method's precision. To assess the precision of the method, samples at the same concentration levels as in case of accuracy evaluation $(80,100$, and $120 \%$ for active pharmaceutical ingredient and LOQ, 100 and $120 \%$ for impurities) were used. At each concentration level every sample was analyzed in triplicate, so the agreement between consecutive measurements was interpreted as relative standard deviation, namely the measure of precision.

Sample solutions. Real sample analysis was performed on Coraxan film-coated tablets. The 20 tablets were accurately weighted and used for calculation of average mass. The tablets were finally powdered and amount of powder containing $38.40 \mathrm{mg}$ of ivabradine was measured and transferred into a $10 \mathrm{~mL}$ volumetric flask by adding a mixture of acetonitrile:water 50:50 (v/v). The obtained solution was ultrasonicated for $30 \mathrm{~min}$ and the mixture was filled to volume of $10 \mathrm{~mL}$ with the same solvent. The solution was filtered through 0.45 $\mu \mathrm{m}$ syringe filter prior to injection. The concentration of ivabradine in the stock sample solution was $3.84 \mathrm{mg} \mathrm{mL}^{-1}$. The stock sample solution was further used to prepare the final sample solution by taking $6.25 \mathrm{~mL}$ of the stock solution and transferring it to the $10 \mathrm{~mL}$ volumetric flask, filled to the volume with the acetonitrile mixed with $20 \mathrm{mM}$ ammonium acetate buffer solution pH 7.33 (15:75, v/v) afterward.

Previously constructed calibration curves were used to calculate the content of API and impurities.

Due to the known photosensitivity of ivabradine, all prepared solutions were protected from daylight and stored in amber glass flasks. The standard solutions were prepared prior to analysis and were stored in the autosampler, whose temperature was kept at $2-8{ }^{\circ} \mathrm{C}$.

\section{Software}

Gradient elution time, $\mathrm{pH}$ value of the aqueous phase, initial and final acetonitrile content of the mobile phase were
Table 1. Key method parameters (KMPs) and defined knowledge space

\begin{tabular}{lccc}
\hline & \multicolumn{3}{c}{$\begin{array}{c}\text { Defined levels of the } \\
\text { variables }\end{array}$} \\
\cline { 2 - 4 } Investigated variables & -1 & 0 & +1 \\
\hline Initial amount of acetonitrile $(\%, v / v)$ & 10.0 & 12.5 & 15.0 \\
Final amount of acetonitrile $(\%, v / v)$ & 30 & 35 & 40 \\
Gradient time (min) & 35 & 45 & 55 \\
pH value of the aqueous part of the & 6.00 & 6.75 & 7.50 \\
$\quad$ mobile phase & & & \\
\hline
\end{tabular}

varied using an experimental design methodology and their corresponding ranges are shown in Table 1. Box-Behnken design (BBD) served to properly cover the experimental space. BBD plan of experiments together with obtained responses (resolutions between critical peak pears) is presented in Table 2.

Design Expert 11.0.0 (Stat-Ease ${ }^{\circledR}$, Minneapolis, Minnesota, USA) was used for both experimental plan construction and statistical analysis of the obtained results.

Grid point search, Monte Carlo simulations and DS graphical presentation were done in Matlab R2018b (Mathworks, Natick, MA, USA).

\section{RESULTS AND DISCUSSION}

$\mathrm{AQbD}$ is a well-structured approach whose outcome is well understood, fit for purpose and robust method that consistently delivers the intended performance throughout its lifecycle. ATP is the foundation of AQbD stating the intended purpose of the method and a priori defined quality criteria for results generated by analytical method. In this particular research, the aim was efficient baseline separation and accurate determination of ivabradine and its eleven impurities from tablets. The performance criteria or CMAs were resolutions between critical peak pairs with quality requirement Rs $\geq 1.5$ and probability $\pi \geq 95 \%$ of having CMAs superior to a selected quality level.

\section{Robust optimization of gradient RP-HPLC method for separation of ivabradine and its structurally related substances supported by AQbD}

Preliminary experiments supported with previously gained knowledge were used to define variables and their domains for gradient elution RP-HPLC method optimization. Throughout the previously developed isocratic method optimization, variables with statistically significant influence on chromatographic behavior of the examined complex mixture were singled out [14]. Those encompassed type and content of organic modifier in the mobile phase, buffer type and its concentration in the aqueous phase, $\mathrm{pH}$ of the aqueous phase and variables related to the slope of the gradient. The slope of the gradient methods is designated with the initial and final amount of the acetonitrile as well as the gradient time. 
Table 2. Plan of experiments of Box-Behnken design and experimentally obtained resolutions for critical peak pairs

\begin{tabular}{|c|c|c|c|c|c|c|c|c|c|}
\hline \multicolumn{10}{|c|}{ Investigated variables with their domains } \\
\hline $\mathrm{A}$ & $\mathrm{B}$ & $\mathrm{C}$ & $\mathrm{D}$ & $\mathrm{Rs}_{\mathrm{III}-\mathrm{V}}$ & $\mathrm{Rs}_{\mathrm{V}-\mathrm{VI}}$ & $\mathrm{Rs}_{\text {IV-VII_1 }}$ & $\mathrm{Rs}_{\text {Ivabr-VII_2 }}$ & $\mathrm{Rs}_{\text {Ivbr-IX }}$ & $\mathrm{Rs}_{\mathrm{IX}-\mathrm{VIII}}$ \\
\hline 10.0 & 30 & 45 & 6.75 & 0.85 & 1.49 & 3.72 & 0.78 & 1.17 & 1.87 \\
\hline 15.0 & 30 & 45 & 6.75 & 0.14 & 0.83 & 2.85 & 1.58 & 1.05 & 1.48 \\
\hline 10.0 & 40 & 45 & 6.75 & 0.00 & 1.44 & 2.92 & 1.31 & 1.21 & 1.19 \\
\hline 15.0 & 40 & 45 & 6.75 & 0.35 & 0.09 & 3.82 & 1.27 & 1.07 & 1.71 \\
\hline 12.5 & 35 & 35 & 6.00 & 0.34 & 0.81 & 7.22 & 1.95 & 1.43 & 1.03 \\
\hline 12.5 & 35 & 55 & 6.00 & 0.02 & 0.40 & 8.91 & 1.98 & 0.95 & 1.54 \\
\hline 12.5 & 35 & 35 & 7.50 & 1.05 & 1.41 & 0.47 & 1.06 & 1.57 & 1.73 \\
\hline 12.5 & 35 & 55 & 7.50 & 1.39 & 2.65 & 0.89 & 1.18 & 1.84 & 1.34 \\
\hline 10.0 & 35 & 45 & 6.00 & 0.25 & 0.54 & 9.16 & 1.61 & 1.38 & 1.31 \\
\hline 15.0 & 35 & 45 & 6.00 & 0.15 & 0.65 & 6.63 & 2.84 & 1.41 & 1.58 \\
\hline 10.0 & 35 & 45 & 7.50 & 1.05 & 3.72 & 2.42 & 1.86 & 1.99 & 1.96 \\
\hline 15.0 & 35 & 45 & 7.50 & 1.00 & 1.45 & 1.44 & 1.33 & 1.68 & 1.6 \\
\hline 12.5 & 30 & 35 & 6.75 & 0.98 & 1.53 & 3.08 & 1.05 & 1.07 & 1.39 \\
\hline 12.5 & 40 & 35 & 6.75 & 0.10 & 0.10 & 2.48 & 1.25 & 0.99 & 1.42 \\
\hline 12.5 & 30 & 55 & 6.75 & 0.45 & 0.80 & 1.97 & 1.44 & 0.97 & 1.59 \\
\hline 12.5 & 40 & 55 & 6.75 & 0.30 & 1.36 & 4.12 & 1.29 & 1.02 & 1.33 \\
\hline 10.0 & 35 & 35 & 6.75 & 0.15 & 0.89 & 3.88 & 0.73 & 1.16 & 1.28 \\
\hline 15.0 & 35 & 35 & 6.75 & 0.68 & 0.09 & 3.00 & 1.35 & 0.90 & 1.57 \\
\hline 10.0 & 35 & 55 & 6.75 & 1.15 & 1.65 & 2.79 & 1.201 & 0.73 & 1.6 \\
\hline 15.0 & 35 & 55 & 6.75 & 0.00 & 0.16 & 5.51 & 1.46 & 1.03 & 1.48 \\
\hline 12.5 & 30 & 45 & 6.00 & 0.25 & 1.22 & 7.21 & 2.25 & 1.16 & 1.89 \\
\hline 12.5 & 40 & 45 & 6.00 & 0.25 & 0.51 & 6.35 & 1.93 & 1.71 & 1.08 \\
\hline 12.5 & 30 & 45 & 7.50 & 1.25 & 1.95 & 0.14 & 1.22 & 1.96 & 1.43 \\
\hline 12.5 & 40 & 45 & 7.50 & 1.35 & 3.17 & 0.40 & 1.22 & 1.46 & 1.84 \\
\hline 12.5 & 35 & 45 & 6.75 & 1.45 & 0.30 & 5.04 & 1.92 & 1.16 & 1.71 \\
\hline 12.5 & 35 & 45 & 6.75 & 0.95 & 0.53 & 5.89 & 1.90 & 1.36 & 1.74 \\
\hline 12.5 & 35 & 45 & 6.75 & 1.10 & 0.71 & 5.26 & 2.07 & 1.15 & 1.81 \\
\hline 12.5 & 35 & 45 & 6.75 & 0.85 & 0.44 & 6.03 & 1.66 & 1.26 & 1.85 \\
\hline 12.5 & 35 & 45 & 6.75 & 1.11 & 0.62 & 5.58 & 2.05 & 1.40 & 1.89 \\
\hline
\end{tabular}

A - initial amount of acetonitrile as organic mobile phase modifier (\%, v/v); B - final amount of acetonitrile as organic mobile phase modifier (\%, v/v); C - gradient time in minutes; $\mathrm{D}$ - pH value of the aqueous part of the mobile phase, Rs - resolution between critical peak pair.

In the light of defined study goals, acetonitrile was selected as the most suitable organic modifier. Acetonitrile was considered golden standard among organic modifiers due to its exceptional physicochemical characteristics. Furthermore, it is shown that acetonitrile forms thick adsorbed layer on the stationary phase surface influencing in this way the analyte's retention and possibly enabling separation of impurity $\mathrm{X}$ diastereoisomers in isocratic elution mode [24]. In this way the possibility to separate diastereoisomers using acetonitrile as organic modifier in gradient elution mode could be estimated. The preliminary experiments were conducted in order to define domains of the initial and final amount of the organic modifier during gradient elution. In fact, the initial amount of acetonitrile was chosen according to the elution time of compounds with the highest polarity in the mixture, impurity I and II. When acetonitrile amount was above $15 \%(\mathrm{v} / \mathrm{v})$, impurities I and II could not be retained on the column, while with acetonitrile content below $10 \%(\mathrm{v} / \mathrm{v})$ their retention times were overly long. The domains of the final amount of the acetonitrile were chosen based on the retention factors of ivabradine and impurities IX and VIII as the most lipophilic ones. The gradient time was varied from 35 to 55 min taking into consideration the complexity of the studied mixture and consequent re-equilibration step which would contribute to further prolongation of the analysis time, respectively. The elution and separation of all compounds should be enabled within the defined domains. Linear gradient was chosen due to its simplicity and suitability for potential method transfer. During preliminary experiments segmentation of the gradient elution was tested as well, but no improvement in separation was achieved. The segmentation of the gradient only led to prolonged retention times.

The ammonium acetate buffer was chosen since it enabled satisfactory peak shapes of ivabradine and its impurities. Our previous study pointed out that concentration of the buffer has no statistically significant impact on chromatographic behavior of investigated analytes. Therefore, the buffer concentration was kept at $20 \mathrm{mM}$, as it was sufficient to enable satisfactory peak symmetries.

The domains should be assigned to one more variable, $\mathrm{pH}$ value of the aqueous phase. In the previous study, the $\mathrm{pH}$ domain encompassed mildly acidic values. However, preliminary experiments revealed that when $\mathrm{pH}$ value of the 
aqueous phase was below 6.00, all compounds eluted earlier disabling the appropriate separation of the compounds. Mentioned chromatographic behavior was expected since most of the analyzed substances compounds with basic characteristics. In the acidic environment the substances are in their ionized forms and consequently less retained. The upper value of the $\mathrm{pH}$ was defined by the characteristics of the used chromatographic column and it was set to 7.50.

All presented variables and their domains were determined (Table 1) and represented the defined knowledge space and KMPs. Resolutions between critical peak pears were selected as CMAs. The examined resolutions were between the following compounds: impurities III and $\mathrm{V}$ $\left(\mathrm{R}_{\text {sIII-V }}\right)$, impurities $\mathrm{V}$ and $\mathrm{VI}\left(\mathrm{R}_{\mathrm{sV}-\mathrm{VI}}\right)$, impurities IV and VII_1 ( $\left.\mathrm{R}_{\text {sIV-VII_1 }}\right)$, ivabradine and impurity VII_2 ( $\mathrm{R}_{\text {sIvabra- }}$ dine-VII_2 $)$, ivabradine and impurity IX ( $\left.\mathrm{R}_{\text {sIvabradine-IX }}\right)$, and impurities IX and VIII ( $\left.\mathrm{R}_{\text {sIX-VIII }}\right)$.

AQbD implies application of DoE among which BBD was selected as optimization design with reasonable number of experiments to be executed in investigation of four KMPs in order to obtain relevant mathematical models. The experimental plan along with the obtained responses is presented in Table 2. Experiments were performed randomly with five replicates in the central point, to provide a precise estimation of an experimental error and obtain valid conclusions.

Responses were obtained following the experimental plan and served for consequent construction of mathematical models. Design Expert proposed square root transformation for response $\mathrm{Rs}_{\text {III-V }}$ while other responses required no transformation. Regarding the proposed models, the best fit for all responses was achieved with a quadratic model. Coefficients of mathematical models obtained for coded values of investigated variables along with their corresponding $\mathrm{p}$-values are presented in Table 3. A positive sign of the coefficient indicates that an increase in the variable value leads to an increase in the response value and vice versa. However, the statistical significance of the variables is estimated using corresponding p-values for all coefficients. Variables with coefficients' corresponding p-values below 0.05 were considered statistically significant. In other words, these variables significantly impact the response change. The most influential variable was $\mathrm{pH}$ value of the aqueous phase, with the highest value of corresponding coefficient that was also statistically significant in all models (Table 3). In order to use the obtained models in the optimization process the adequacy of the models had to be demonstrated through Lack of Fit values and coefficients of determination $\left(R^{2}\right)$. If p-value corresponding to Lack of fit is above 0.05 , the mathematical model is valid and suitable to describe the influence of the examined variables towards response. The Lack of fit values for all mathematical models are shown in Table 3 and indicate the proper and insignificant error of the models. Values of $R^{2}$ and adjusted $R^{2}$ were above 0.874 for all responses (Table 3 ) pointing out the good predictive ability of all models. Aforementioned results indicated that all investigated variables are significant towards examined responses.
The second step was to perform the modeling of the defined critical responses. Knowledge space was gridded by discretization of initial [10:0.5:15] and final [30:0.5:40] content of acetonitrile and $\mathrm{pH}$ value of the aqueous phase [6.0:0.075:7.5]. Factor C - gradient time was not included in the discretization and its value was fixed at $45 \mathrm{~min}$. Such decision was supported by the fact that the model coefficient corresponding to this variable was significant only for response $\mathrm{Rs}_{\mathrm{V} \text {-VI }}$ suggesting this factor affects studied system the least. When discretization level is taken into account, 11, 21 , and 21 points were obtained for each KMP respectively and the total number of points was 4,851 . Knowledge space has to be explored according to defined ATP, regarding all CMAs and probability of $95 \%$ to meet quality limit Rs $\geq 1.5$. In this way, part of the knowledge space where all method development goals are fulfilled could be discovered and represents DS [21, 25]. Risk assessment is done using Monte Carlo simulation with 5,000 iterations to propagate the error in each point of the knowledge space. The error that was used refers to calculated standard error of model coefficients which were obtained in the Design Expert along with model coefficients. The uniform error distribution equal to the calculated standard error was added to the model coefficient estimates in order to obtain predictive distribution of CMAs' for each operating condition corresponding to a grid of 4,851 points. In this way the extraction of the region of DS from the knowledge space having the satisfactory values of all critical resolutions with desired quality level with probability $\pi=95 \%$ was done. The quality of DS is not only assured but also the risk of CMAs not being within the acceptance level was assessed.

Unfortunately, for this defined criteria no DS was achieved. Analyzing all responses separately, as well as the level of their goals' fulfillment the following problem occurred. Adequate separation of impurities III and V could not be achieved within defined experimental domains since the maximum resolution value obtained was only 1.454. Chromatographic conditions that lead to the highest values of $\mathrm{Rs}_{\text {III-V }}$ jeopardized some of the remaining responses. For this reason, $\mathrm{R}_{\text {sIII-V, }}$ though critical, was omitted from the optimization process and no criterion was defined for it. For the remaining five responses the described statistical analysis was repeated. It was decided to construct three different DSs for gradient elution times of 35,45 , and $55 \mathrm{~min}$. The selection of robust optimal conditions should be followed by reasonable timeframe of the chromatographic analysis as well. It appeared that DS was obtained only when gradient retention time was set to $45 \mathrm{~min}$ (Fig. 2c). Endeavor to achieve insight into the chromatographic separation within gradient elution time, DSs were further constructed for gradient elution time of 41,43,45, 47, 49, and $51 \mathrm{~min}$ (Fig. 2). When gradient elution time was set to $41 \mathrm{~min}$ the DS (Fig. 2a) represented the cavity shaped contour suggesting no robust chromatographic conditions. The situation significantly improved when gradient elution time was extended to $43 \mathrm{~min}$ (Fig. $2 \mathrm{~b}$ ) resulting in a cone shaped DS, offering optimal chromatographic conditions in the center of the cone. Further extension led to a larger 
Table 3. Coefficients of the mathematical models for the critical peak pairs resolutions, their corresponding $P$-values and coefficients of determination

\begin{tabular}{|c|c|c|c|c|c|c|c|c|c|c|c|c|}
\hline $\begin{array}{l}\text { Response } \\
\text { Model coefficients }\end{array}$ & Sqrt $\left(\mathrm{Rs}_{\text {III-V) }}\right.$ & $P$-value & $\mathrm{Rs}_{\mathrm{V}-\mathrm{VI}}$ & $P$-value & $\mathrm{Rs}_{\text {IV-VII_1 }}$ & $P$-value & $\mathrm{Rs}_{\text {Ivabr-VII_2 }}$ & $P$-value & $\mathrm{Rs}_{\text {Ivbr-IX }}$ & $P$-value & $\mathrm{Rs}_{\mathrm{IX}-\mathrm{VIII}}$ & $P$-value \\
\hline Intersept & 1.0400 & $<10^{-4}$ & 0.5206 & $<10^{-4}$ & 5.5600 & $<10^{-4}$ & 1.9200 & $<10^{-4}$ & 1.2600 & $<10^{-4}$ & 1.8000 & $<10^{-4}$ \\
\hline A & -0.0614 & $<10^{-4}$ & -0.5380 & $<10^{-4}$ & -0.1373 & 0.500 & 0.1943 & 0.001 & -0.0416 & 0.141 & 0.0164 & 0.434 \\
\hline B & -0.1183 & 0.002 & -0.0951 & 0.150 & 0.0922 & 0.649 & -0.0046 & 0.924 & 0.0065 & 0.811 & -0.0893 & 0.001 \\
\hline $\mathrm{C}$ & -0.0423 & 0.132 & 0.1803 & 0.012 & 0.3376 & 0.111 & 0.0958 & 0.063 & -0.0483 & 0.092 & 0.0423 & 0.057 \\
\hline $\mathrm{D}$ & 0.3252 & $<10^{-4}$ & 0.8523 & $<10^{-4}$ & -3.3100 & $<10^{-4}$ & -0.3918 & $<10^{-4}$ & 0.2054 & $<10^{-4}$ & 0.1240 & $<10^{-4}$ \\
\hline $\mathrm{AB}$ & 0.2783 & 0.117 & -0.1717 & 0.134 & 0.4420 & 0.219 & -0.2105 & 0.023 & -0.0062 & 0.894 & 0.2283 & $<10^{-4}$ \\
\hline $\mathrm{AC}$ & -0.3695 & 0.336 & -0.1715 & 0.135 & 0.8995 & 0.020 & -0.0902 & 0.291 & 0.1410 & 0.009 & -0.1140 & 0.006 \\
\hline $\mathrm{AD}$ & 0.0229 & 0.003 & -0.5942 & $<10^{-4}$ & 0.3880 & 0.278 & -0.4383 & 0.0001 & -0.0820 & 0.098 & -0.1470 & 0.001 \\
\hline $\mathrm{BC}$ & 0.1370 & 0.028 & 0.4992 & $4 \times 10^{-3}$ & 0.6887 & 0.065 & -0.0890 & 0.297 & 0.0330 & 0.487 & -0.0722 & 0.060 \\
\hline $\mathrm{BD}$ & 0.0105 & 0.278 & 0.4812 & 0.001 & 0.2817 & 0.426 & 0.0787 & 0.354 & -0.2632 & $<10^{-4}$ & 0.3045 & $<10^{-4}$ \\
\hline $\mathrm{CD}$ & 0.1539 & 0.409 & 0.4145 & 0.002 & -0.3165 & 0.373 & 0.0247 & 0.768 & 0.1850 & 0.001 & -0.2245 & $<10^{-4}$ \\
\hline $\mathrm{A}^{2}$ & -0.2875 & $<10^{-4}$ & 0.1602 & 0.080 & -0.5688 & 0.054 & -0.2585 & 0.0013 & -0.0736 & 0.062 & -0.0727 & 0.020 \\
\hline $\mathrm{B}^{2}$ & -0.2163 & $<10^{-4}$ & 0.3471 & 0.001 & -1.7000 & $<10^{-4}$ & -0.3499 & $<10^{-4}$ & -0.0629 & 0.105 & -0.1363 & $2 / 10^{-3}$ \\
\hline $\mathrm{C}^{2}$ & -0.2113 & $<10^{-4}$ & 0.0176 & 0.84 & -1.0500 & 0.002 & -0.4340 & $<10^{-4}$ & -0.2117 & $<10^{-4}$ & -0.2437 & $<10^{-4}$ \\
\hline $\mathrm{D}^{2}$ & -0.0419 & $<10^{-4}$ & 0.8449 & $<10^{-4}$ & -0.1824 & 0.510 & 0.1274 & 0.069 & 0.3969 & $<10^{-4}$ & -0.1186 & 0.001 \\
\hline Lack of Fit & - & 0.275 & - & 0.230 & - & 0.124 & - & 0.536 & - & 0.826 & - & 0.636 \\
\hline $\mathrm{R}^{2}$ & - & 0.928 & - & 0.971 & - & 0.961 & - & 0.939 & - & 0.959 & - & 0.961 \\
\hline Adj $R^{2}$ & - & 0.856 & - & 0.942 & - & 0.922 & - & 0.877 & - & 0.917 & - & 0.922 \\
\hline Pred $R^{2}$ & - & 0.636 & - & 0.852 & - & 0.793 & - & 0.719 & - & 0.839 & - & 0.828 \\
\hline
\end{tabular}

$\mathrm{A}$ - initial amount of acetonitrile as organic mobile phase modifier $(\%, \mathrm{v} / \mathrm{v}) ; \mathrm{B}-$ final amount of acetonitrile as organic mobile phase modifier (\%, $\mathrm{v} / \mathrm{v})$; $\mathrm{C}-$ gradient time in minutes, $\mathrm{D}-\mathrm{pH}$ value of the aqueous part of the mobile phase; $\mathrm{R}^{2}$ - coefficient of determination; Adj. $\mathrm{R}^{2}$ - adjusted coefficient of determination; Pred. $\mathrm{R}^{2}-$ predicted coefficient of determination; Rs - resolution between critical peak pair. 


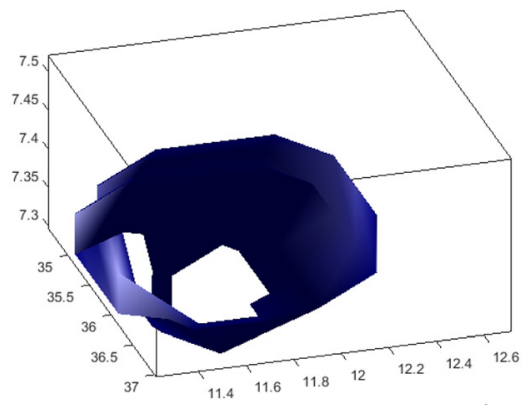

a)

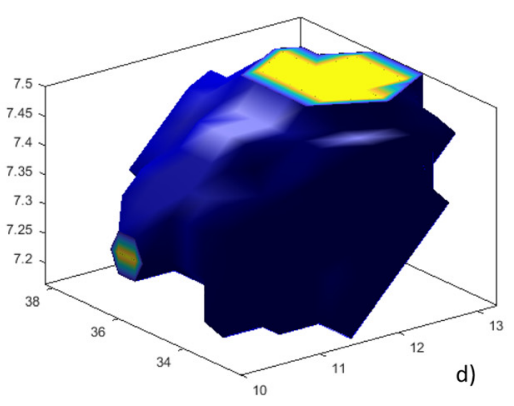

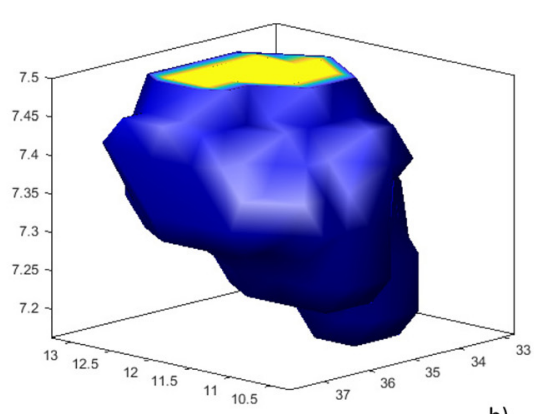

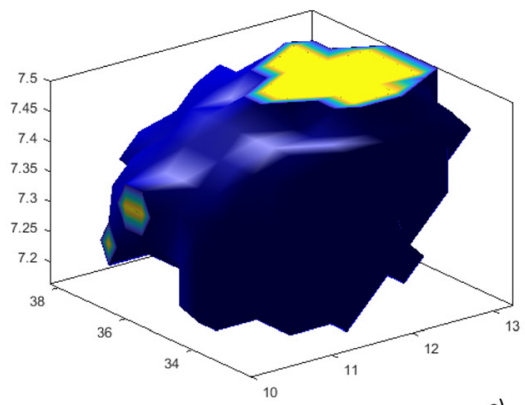

b)

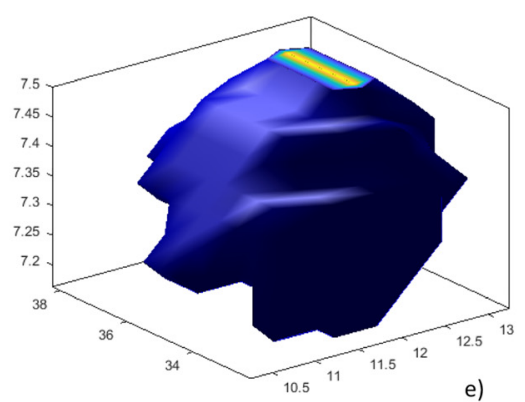

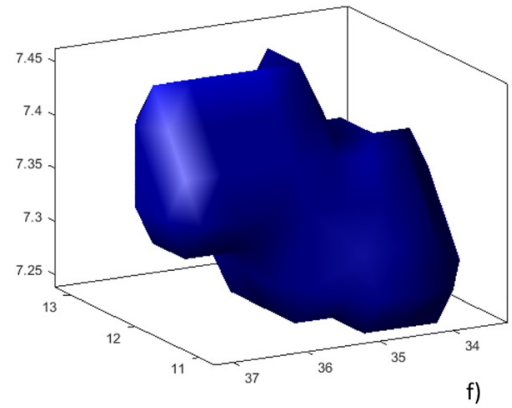

Fig. 2. 3D representation of Design Space for predefined ATP achieved with probability $\pi=95 \%$ for gradient elution time of (a) 41 min, (b) $43 \mathrm{~min}$, (c) $45 \mathrm{~min}$, (d) $47 \mathrm{~min}$, (e) $49 \mathrm{~min}$, and (f) $51 \mathrm{~min}$

irregular shaped DS that enclosed wider set of satisfactory chromatographic conditions. Since further extension of gradient elution time led to smaller DS implying only time-consuming method without any chromatographic improvement, it was decided to choose gradient elution time of $45 \mathrm{~min}$ to be optimal and optimal chromatographic conditions were selected within DS illustrated by Fig. 2c. Though DS was constructed applying risk assessment and theoretically any point should give robust separation, it is advisable to obtain a larger DS and to select a working point in the middle of it and not a superficial one. Taking into account the above stated goals together with the need to produce as low organic waste as possible, optimal chromatographic conditions were selected and included: 11\% (v/ v) and $34 \%(\mathrm{v} / \mathrm{v})$ of initial and final amount of ACN, respectively, and $\mathrm{pH}$ of the aqueous part of the mobile phase 7.35. Another important issue that must be addressed before validation is resolution between ivabradine and impurity VII_2 under optimal chromatographic conditions. Separating API and consequently eluting impurity is always more critical than separating peaks of similar size and shape, therefore resolution threshold is suggested to be above 1.5, and in general around 2 [26-28]. However, in gradient elution mode peak broadening of API and enormous peak tailing is not expected leading to the fact that resolution of 1.5 could work as well. The representative chromatogram obtained under optimal chromatographic conditions is presented in Fig. 3 and baseline separation of all critical peak pairs except impurities III and V was achieved. The proposed gradient elution method has the stability indicating character and could be utilized in assessment of pharmaceutical dosage forms.
It is important to note that keto-enol tautomers of impurity VII are separated when gradient elution was applied, as well. Conversely, diastereoisomers of impurity X could not be separated in gradient elution though acetonitrile was used as the organic modifier. The literature survey suggested that gradient elution methods could be utilized in separation of diastereoisomers as well as some other organic modifiers such as methanol and ethanol [29-31]. At this point no general conclusions could be drawn, but is a good starting point for further research when larger number of diastereoisomers, organic solvents and elution modes will be included.

\section{Validation of gradient RP-HPLC method for separation of ivabradine hydrochloride and its eleven impurities}

The developed method was subjected to final method validation according to International Conference on Harmonization (ICH) Q2 (R1) guideline [32, 33]. There were no interferences originating from Coraxan ${ }^{\circledR}$ film tablets excipients and peak purity of the compounds was 99\%, which supported the selectivity of the method. Limits of detection (LOD) and quantification (LOQ) were determined for all impurities using signal to noise approach (Table 4). According to the method sensitivity, the linearity range of the impurities and consequently ivabradine were determined. The impurities' LOQ values were labeled as the first concentration levels. Their concentration ranges went to the nominal concentration $100 \%$, referring to maximum allowed concentration (MAC), designated in Table 4, and then up to $120 \%$. In that respect, the concentration range of API was selected to enable determination of all impurities present 


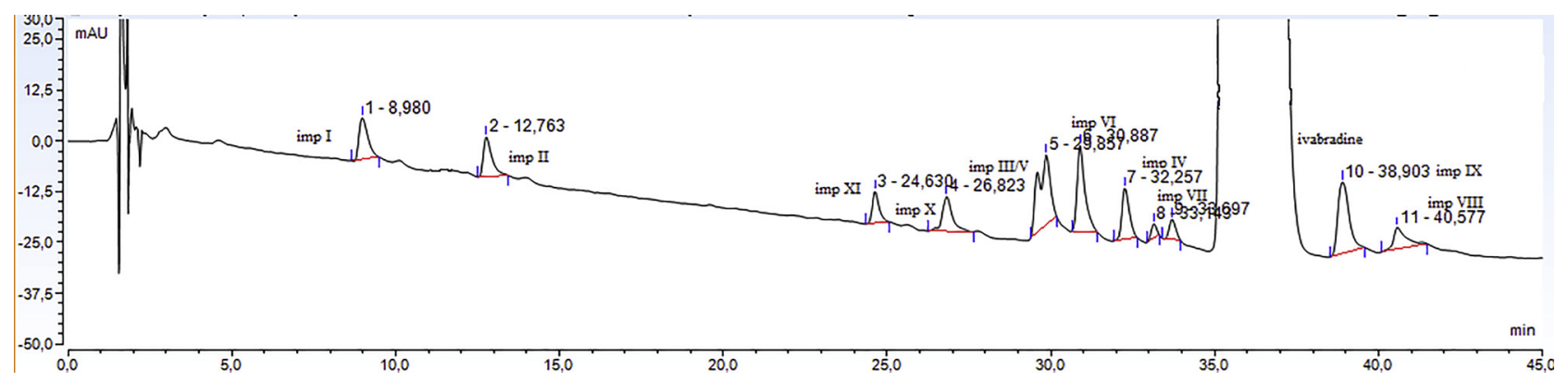

Fig. 3. Representative chromatogram of ivabradine and its eleven impurities separated under optimal chromatographic conditions, which included initial amount of acetonitrile set at $11 \%(\mathrm{v} / \mathrm{v})$, final amount of acetonitrile set at $34 \%(\mathrm{v} / \mathrm{v})$, $\mathrm{pH}$ value of the $20 \mathrm{mM}$ ammonium acetate set at 7.35 and 45 min of the gradient elution time

Table 4. Validation parameters

\begin{tabular}{|c|c|c|c|c|c|c|}
\hline & \multirow[b]{2}{*}{$\begin{array}{c}\mathrm{LOD} \\
\left(\mu \mathrm{g} \mathrm{mL}^{-1}\right)\end{array}$} & \multicolumn{2}{|c|}{ Linearity } & \multirow[b]{2}{*}{$\begin{array}{l}\text { Concentration } \\
\text { level }(\%)\end{array}$} & \multirow{2}{*}{$\begin{array}{l}\text { Accuracy } \\
\text { Recovery } \\
\text { value (\%) }\end{array}$} & \multirow{2}{*}{$\begin{array}{l}\text { Precision } \\
\text { RSD (\%) }\end{array}$} \\
\hline & & $\begin{array}{l}\text { Calibration equation } \\
(y=a x+b)\end{array}$ & $\begin{array}{l}\text { Correlation } \\
\text { coefficient, } r\end{array}$ & & & \\
\hline \multirow[t]{3}{*}{ Ivabradine } & - & $y=546.06 x-32.78$ & 0.9963 & 80 & 100.979 & 1.564 \\
\hline & & & & 100 & 98.457 & 1.124 \\
\hline & & & & 120 & 100.655 & 0.986 \\
\hline \multirow[t]{3}{*}{ Impurity I MAC $0.3 \%$} & 0.499 & $y=0.4527 x-0.7253$ & 0.9816 & LOQ & 105.332 & 8.609 \\
\hline & & & & 100 & 92.189 & 8.690 \\
\hline & & & & 120 & 104.991 & 4.508 \\
\hline \multirow[t]{3}{*}{ Impurity II MAC $0.2 \%$} & 0.466 & $y=0.309 x-0.246$ & 0.9954 & LOQ & 104.094 & 5.430 \\
\hline & & & & 100 & 93.103 & 2.796 \\
\hline & & & & 120 & 104.260 & 8.402 \\
\hline \multirow[t]{3}{*}{ Impurity III and V MAC $0.2 \%$} & 0.490 & $y=0.3702 x-0.251$ & 0.9936 & LOQ & 109.790 & 3.977 \\
\hline & & & & 100 & 94.560 & 4.181 \\
\hline & & & & 120 & 107.435 & 2.579 \\
\hline \multirow[t]{3}{*}{ Impurity IV MAC $0.2 \%$} & 0.240 & $y=0.4205 x-0.2235$ & 0.9938 & LOQ & 90.233 & 2.990 \\
\hline & & & & 100 & 91.986 & 3.258 \\
\hline & & & & 120 & 106.487 & 3.258 \\
\hline \multirow[t]{3}{*}{ Impurity VI MAC $0.2 \%$} & 0.336 & $y=0.4926 x-0.2891$ & 0.9977 & LOQ & 97.488 & 6.266 \\
\hline & & & & 100 & 105.194 & 2.896 \\
\hline & & & & 120 & 97.314 & 1.359 \\
\hline \multirow[t]{3}{*}{ Impurity VII-1 MAC $0.6 \%$} & 0.720 & $y=0.1088 x-0.173$ & 0.9915 & LOQ & 90.444 & 3.172 \\
\hline & & & & 100 & 109.528 & 5.569 \\
\hline & & & & 120 & 95.224 & 1.235 \\
\hline \multirow[t]{3}{*}{ Impurity VII-2 MAC $0.6 \%$} & 0.720 & $y=0.2021 x-0.4957$ & 0.9833 & LOQ & 93.849 & 2.730 \\
\hline & & & & 100 & 109.144 & 1.297 \\
\hline & & & & 120 & 97.532 & 4.148 \\
\hline \multirow[t]{3}{*}{ Impurity VIII MAC $0.6 \%$} & 0.240 & $y=0.327 x-0.1561$ & 0.9956 & LOQ & 94.388 & 2.740 \\
\hline & & & & 100 & 109.883 & 0.764 \\
\hline & & & & 120 & 92.935 & 1.284 \\
\hline \multirow[t]{3}{*}{ Impurity IX MAC $0.2 \%$} & 0.116 & $y=0.8409 x-0.2245$ & 0.9857 & LOQ & 104.09 & 0.932 \\
\hline & & & & 100 & 92.862 & 1.566 \\
\hline & & & & 120 & 104.252 & 1.292 \\
\hline \multirow[t]{3}{*}{ Impurity X MAC $0.2 \%$} & 0.324 & $y=0.3994 x-0.1757$ & 0.9807 & LOQ & 101.804 & 2.794 \\
\hline & & & & 100 & 96.848 & 8.819 \\
\hline & & & & 120 & 101.906 & 6.892 \\
\hline \multirow[t]{3}{*}{ Impurity XI MAC $0.2 \%$} & 0.605 & $y=0.153 x-0.1463$ & 0.9859 & LOQ & 110.01 & 1.671 \\
\hline & & & & 100 & 101.97 & 2.757 \\
\hline & & & & 120 & 106.943 & 2.844 \\
\hline
\end{tabular}

$\mathrm{r}$ - correlation coefficient (acceptance value $>0.99$ for active compounds, $>0.98$ for impurities); Recovery: $98.0-102.0 \%$ for active compounds, $90-110 \%$ for impurities with the specification limit of $0.2-0.6 \%$; RSD: $\leq 2 \%$ for active compounds, $\leq 10 \%$ for impurities with the specification limit of $0.2-0.6 \%$. 
from LOQ to MAC. The correlation coefficients obtained after applying linear least squares regression indicated the linearity of all calibration curves, since in cases of ivabradine and impurities they were greater than 0.99 and 0.98 , respectively $[34,35]$. In order to avoid the possibility of matrix effects, for quantification of impurities, the methodology of standard addition was used [35, 36]. This methodology provided reliable measurements. Obtained values of relative standard deviation for ivabradine and eleven impurities met the acceptance criteria, thus confirming the method's precision. RSD should not exceed $2 \%$ in case of ivabradine, while in case of eleven impurities with the specification limit between 0.2 and $0.6 \%$, RSD should not exceed $10 \%$ [27]. For the method accuracy investigations, recovery values were within $\pm 2 \%$ for ivabradine and within $\pm 10 \%$ for eleven impurities [34]. Validation results are presented in Table 4 in more detail.

After analysis of the sample solution, it was revealed that ivabradine content in the dosage form was $99.12 \%$ that correspond to $7.43 \mathrm{mg}$ per tablet. The impurity $\mathrm{X}$ was the only impurity found in the sample solution and its content corresponded to the $0.1 \%$. This was below defined MAC of $0.2 \%$ for impurity $\mathrm{X}$.

\section{CONCLUSION}

An improved gradient elution RP-HPLC method was developed applying AQbD approach. Direct modeling of resolution of critical peak pairs and construction of DS enabled the development of a robust HPLC method. This was essential since a complex mixture of ivabradine and eleven structural related compounds had to be separated in a reasonable time frame. The optimal gradient time was 45 min with additional re-equilibration of $10 \mathrm{~min}$. All compounds were successfully separated except two positional isomers, impurities III and V. However, positional isomers do not emerge as a result of degradation process in tablets. In that sense, the proposed method could be used for assessment of ivabradine and its degradation products in pharmaceutical dosage forms. In addition, it was confirmed that keto-enol tautomers of impurity VII can be separated using gradient elution mode unlike diastereoisomers of impurity X. The applicability of proposed method was confirmed since all validation parameters met the criteria defined by ICH guidelines.

Funding: Project no.451-03-68/2020-14/200161, financed by the Ministry of Education, Science and Technological Development of the Republic of Serbia.

Authors' contribution: Jovana Tomić - Formal analysis, Writing - Original Draft.

Nevena Djajić - Methodology, Investigation, Writing Original Draft.

Danica Agbaba - Resources, Funding acquisition, Supervision.
Biljana Otašević - Software, Writing - Review and Editing.

Andjelija Malenović - Software, Writing - Review and Editing.

Ana Protić - Conceptualization, Supervision, Resources.

Conflicts of interest: The authors declare that they have no conflict of interest.

\section{ACKNOWLEDGMENT}

These results are part of the Project no. 451-03-68/2020-14/ 200161, financed by the Ministry of Education, Science and Technological Development of the Republic of Serbia.

\section{REFERENCES}

1. Andrikopoulos, G.; Dasopoulou, C.; Sakellariou, D.; Tzeis, S.; Koulouris, S.; Kranidis, A; Kappos, K.; Manolis, A.S. Ivabradine: a selective if current inhibitor in the treatment of stable angina. Rec. Patents Cardiovasc. Drug Discov. 2006, 1(3), 277-82.

2. Su, J. B. Cardioprotective effects of the if current inhibition by ivabradine during cardiac dysfunction. Curr. Pharm. Biotechnol. 2013, 14(14), 1213-9.

3. Klippert, P., Jeanniot, J.-P., Polvé, S., Lefevre, C., Merdjan, H. Determination of ivabradine and its $\mathrm{N}$-demethylated metabolite in human plasma and urine, and in rat and dog plasma by a validated high-performance liquid chromatographic method with fluorescence detection. J. Chromatogr. B: Biomed. Sci. Appl. 1998, 719(1-2), 125-233.

4. Lu, C.; Jia, Y., Yang, J.; Jin, X.; Song, Y.; Liu, W.; Dinga, Y.; Sun, X.; Wena, A. Simultaneous determination of ivabradine and N-desmethylivabradine in human plasma and urine using a LC-MS/MS method: application to a pharmacokinetic study. Acta Pharmac. Sinica B 2012, 2(2), 205-12.

5. François-Bouchard, M.; Simonin, G.; Bossant, M.-J.; BoursierNeyret, C. Simultaneous determination of ivabradine and its metabolites in human plasma by liquid chromatography-tandem mass spectrometry. J. Chromatogr. B: Biomed. Sci. Appl. 2000, 745(2), 261-9.

6. Sun, W.; Chen, R.; Li, W.; Zhang, H.; Ye, J.; Cui, X.; Huang, C. Simultaneous determination of ivabradine, metoprolol and their metabolites in rat plasma by ultra-performance liquid chromatography tandem mass spectrometry and its application in a pharmacokinetic study. Anal. Methods 2015, 7(19), 8459-65.

7. Zoerner, A. A.; Schroeder, C.; Kayacelebi, A. A.; Suchy, M. T.; Gutzki, F.-M.; Stichtenoth, D. O.; Tank, J.; Jordan, J.; Tsikas, D. A validated, rapid UPLC-MS/MS method for simultaneous ivabradine, reboxetine, and metoprolol analysis in human plasma and its application to clinical trial samples. J. Chromatogr. B 2013, 927, 105-11.

8. Damle, M.; Bagwe, R. Development and validation of stabilityindicating HPTLC method for ivabradine HCl. Pharm. Sci. Monitor 2015, 6(1), 141-52.

9. Nowakowska, J.; Pikul, P.; Marszałł, M.; Ciura, K. Application and validation of simple isocratic HPLC-UV-DAD method with dual 
wavelength detection for Ivabradine determination and its application in the study of stress degradation. J. Chem. 2017, 2017.

10. Maheshwari, S.; Khandhar, A. P.; Jain, A. Quantitative determination and validation of ivabradine $\mathrm{HCl}$ by stability indicating RPHPLC method and spectrophotometric method in solid dosage form. Eurasian J. Anal. Chem. 2010, 5(1), 53-62.

11. Patel, P. N.; Borkar, R. M.; Kalariya, P. D.; Gangwal, R. P.; Sangamwar, A. T.; Samanthula, G.; Ragampeta, S. Characterization of degradation products of Ivabradine by LC-HR-MS/MS: a typical case of exhibition of different degradation behaviour in $\mathrm{HCl}$ and $\mathrm{H} 2 \mathrm{SO} 4$ acid hydrolysis. J. Mass Spectrom. 2015, 50(2), 344-53.

12. Pikul, P.; Jamrógiewicz, M.; Nowakowska, J.; Hewelt-Belka, W.; Ciura, K. Forced degradation studies of ivabradine and in silico toxicology predictions for its new designated impurities. Front. Pharmacol. 2016, 7, 117.

13. Gangrade, D.; D'Souza, J. A simple and sensitive RP-HPLC method for trace-level quantification of methyl vinyl-ketone, a potential genotoxic impurity, in drug substances. Int. J. Pharm. Sci. Res. 2017, 8(2), 706.

14. Tomić, J.; Ivković, B.; Oljačić, S.; Nikolić, K.; Maljurić, N.; Protić, A.; Agbaba, D. Chemometrically assisted RP-HPLC method development for efficient separation of ivabradine and its eleven impurities. Acta Chromatogr. 2019, 1-11.

15. Kochling, J.; Wu, W.; Hua, Y.; Guan, Q.; Castaneda-Merced, J. A platform analytical quality by design (AQbD) approach for multiple UHPLC-UV and UHPLC-MS methods development for protein analysis. J. Pharm. Biomed. Anal. 2016, 125, 130-9.

16. Dispas, A.; Avohou, H. T.; Lebrun, P.; Hubert, P.; Hubert, C. 'Quality by Design'approach for the analysis of impurities in pharmaceutical drug products and drug substances. Trac Trends Anal. Chem. 2018, 101, 24-33.

17. Vogt, F. G.; Kord, A. S. Development of quality-by-design analytical methods. J. Pharm. Sci. 2011, 100(3), 797-812.

18. Reid, G. L.; Morgado, J.; Barnett, K.; Harrington, B.; Wang, J.; Harwood, J.; Fortin, D. Analytical quality by design (AQbD) in pharmaceutical development. Am. Pharm. Rev. 2013, 144191.

19. ICH of Techical Requirements for Registration of Pharmaceuticals for Human Use; Q8 R2 Pharmaceutical Development, http://www. ich.org/fileadmin/Public Web Site/ICH Products/Guidelines/ Quality/Q8 RI/Step4/Q8 R2 Guidelines [cited accessed June 2011].

20. Orlandini, S.; Pasquini, B.; Stocchero, M.; Pinzauti, S.; Furlanetto, S. An integrated quality by design and mixture-process variable approach in the development of a capillary electrophoresis method for the analysis of almotriptan and its impurities. J. Chromatogr. A 2014, 1339, 200-9.

21. Rozet, E.; Lebrun, P.; Hubert, P.; Debrus, B.; Boulanger, B. Design spaces for analytical methods. Trac Trends Anal. Chem. 2013, 42, 157-67.
22. International Conference on Harmonization (ICH) of Technical Requirements for Registration of Pharmaceuticals for Human Use; Topic Q9: Quality risk management. Federal Register: Geneva, Switzerland. 2006, 71(106), 32105-6.

23. International Conference on Harmonization (ICH) of Technical Requirements for Registration of Pharmaceuticals for Human Use; Topic Q10: Pharmaceutical Quality System. Federal Register: Geneva, Switzerland. 2009, 74(66), 15990-1.

24. Kazakevich, Y.; LoBrutto, R.; Chan, F.; Patel, T. Interpretation of the excess adsorption isotherms of organic eluent components on the surface of reversed-phase adsorbents: effect on the analyte retention. J. Chromatogr. A 2001, 913(1-2), 75-87.

25. Vemić, A.; Stojanović, B. J.; Stamenković, I.; Malenović, A. Chaotropic agents in liquid chromatographic method development for the simultaneous analysis of levodopa, carbidopa, entacapone and their impurities. J. Pharm. Biomed. Anal. 2013, 77, 9-15.

26. Snyder, L. R.; Kirkland, J. J.; Dolan, J. W. Introduction to Modern Liquid Chromatography; John Wiley \& Sons, 2011.

27. Šljivić, J.; Protić, A.; Malenović, A.; Otašević, B.; Zečević, M. Simple and efficient solution for robustness testing in gradient elution liquid chromatographic methods. Chromatographia 2018, 81(8), 1135-45.

28. Klein, E. J.; Rivera, S. L. A review of criteria functions and response surface methodology for the optimization of analytical scale HPLC separations. J. Liquid Chromatogr. Related Technol., 2000, 23(14), 2097-121.

29. Vanbilloen, H.; Cleynhens, B.; De Groot, T.; Maes, A.; Bormans, G.; Verbruggen, A. RP-HPLC separation of the diastereomers of technetium-99m labelled tropanes and identity confirmation using radio-LC-MS. J. Pharm. Biomed. Anal. 2003, 32(4-5), 663-8.

30. Ding, T.-m.; Tian, S.-j.; Zhang, Z.-x.; Gu, D.-Z.; Chen, Y.-f.; Shi, Y.h.; Sun, Z. Determination of active component in silymarin by RPLC and LC/MS. J. Pharm. Biomed. Anal. 2001, 26(1), 155-61.

31. Nagai, T.; Kurosu, A.; Matsushima, K.; Maeda, J.; Tohei, A.; Yamauchi, S.; Hitosugi, M.; Tokudome, S. Simultaneous identification of the enantiomers and diastereomers of $\mathrm{N}$, O-Di-trifluoroacetylated ephedrine and norephedrine in blood plasma using chiral capillary gas chromatography-mass spectrometry with selected ion monitoring. J. Anal. Toxicol. 2012, 36(2), 96-105.

32. Guideline ICH. Q2 (R1). Validation of Analytical Procedures: Text and Methodology, 2005.

33. Ermer, J.; Miller, J. H. M. Method Validation in Pharmaceutical Analysis: A Guide to Best Practice; John Wiley \& Sons, 2006.

34. Ahuja, S.; Scypinski, S. Handbook of Modern Pharmaceutical Analysis; Academic Press, 2010.

35. Fifield, F. W.; Kealey, D. Principles and Practice of Analytical Chemistry; Blackwell Science Ltd, 2000.

36. Harris, D. C. Quantitative Chemical Analysis; Macmillan, 2010.

Open Access. This is an open-access article distributed under the terms of the Creative Commons Attribution-NonCommercial 4.0 International License (https:// creativecommons.org/licenses/by-nc/4.0/), which permits unrestricted use, distribution, and reproduction in any medium for non-commercial purposes, provided the original author and source are credited, a link to the CC License is provided, and changes - if any - are indicated. 